\title{
Pelatihan Perawatan dan Service Sepeda Motor Bagi Pemuda Putus Sekolah di Ogan Ilir
}

\author{
Motorcycle Maintenance and Service Training for School Dropouts in Ogan \\ Ilir
}

\author{
Dewi Puspita Sari*, Harlin, \& Wadirin \\ Universitas Sriwijaya, Indralaya, Sumatera Selatan, Indonesia \\ dewipuspita@fkip.unsri.ac.id*
}

Naskah diterima tanggal 10/12/2020, direvisi akhir tanggal 23/12/2020, disetujui tanggal 30/04/2021

\begin{abstract}
Abstrak
Rata-rata anak putus sekolah yang ada di Kelurahan Permata Baru (Mandala) kecamatan Indralaya Utara Ogan Ilir menginginkan merubah nasib dengan cara mendapatkan penghasilan yang lebih layak dengan pekerjaan yang bisa diandalkan. Kelanjutan dari pembicaraan informal menyimpulkan bahwa mereka menginginkan untuk bisa berusaha sendiri (berwirausaha) yang memiliki core bisnis dengan keterampilan mereka yaitu jasa perbengkelan sepeda motor. Ini karena sepeda motor merupakan kendaraan utama di wilayah mereka sehingga perbengkelan prospektif. Pengabdian masyarakat ini memiliki tujuan memberikan pelatihan keterampilan perawatan dan service sepeda motor seperti tune-up dan dapat mengoperasikan peralatan reparasi secara benar serta penyuluhan tentang bidang mengelola usaha. Pada tahap awal, seluruh peserta dikumpulkan dan diberikan evaluasi awal untuk melihat tingkat pemahaman mereka yang nantinya akan dibandingkan dengan tes akhir (post-test). Selanjutnya, tahap kegiatan, peserta diberikan materi yang berhubungan dengan perawatan dan service sepeda motor, sehingga peserta akan paham tentang materi yang disampaikan. Materi yang disampaikan menggunakan metode ceramah, metode diskusi, demonstrasi dan praktik langsung. Terakhir adalah evaluasi akhir. Tujuan akhir dari kegiatan pengabdian ini adalah memberikan pengetahuan dan pemahaman terhadap bagaimana cara melakukan perawatan dan service sepeda motor. Penilaian keberhasilan dari kegiatan ini dilihat melalui kemajuan pengetahuan dan pemahaman serta keterampilan melalui perbandingan antara tes awal dan tes akhir.
\end{abstract}

Kata kunci: Pelatihan; Perawatan; Service; Sepeda motor.

\section{Abstract}

The average school dropout in Permata Baru (Mandala) subdistrict, Indralaya Utara District, Ogan Ilir, wants to change their fate by getting a more decent income with a reliable job. The informal discussion continued that they wanted to be self-employed (entrepreneurship) with a core business with their skills, namely motorcycle repair services. This is because motorbikes are the primary vehicle in their area so that the repair is prospective. This community service aims to provide training in motorcycle maintenance and service skills such as tune-ups and properly operate reparation equipment and counseling on business management. In the initial stage activity, all participants are gathered and given an initial evaluation to see their level of understanding, which will later be compared with the final test (post-test). Next, participants are given a lesson related to motorcycle maintenance and service to understand the lesson presented in the activity stage. The study showed the lecture method, discussion method, demonstration, and hands-on practice, lastly, in the final evaluation. This service activity aims to provide knowledge and understanding of how to maintain and service motorbikes. Assessment of the success of this activity is seen through the progress of knowledge and 
understanding and skills through a comparison between the pre-test and the post-test.

Keywords: Training; Maintenance; Service; Motorcycle. 


\section{PENDAHULUAN}

Berdasarkan survey awal yang telah dilakukan, rata-rata anak putus sekolah yang ada di kelurahan permata baru (mandala) kecamatan Indralaya Utara Ogan Ilir menginginkan merubah nasib dengan cara mendapatkan penghasilan yang lebih layak dengan pekerjaan yang bisa diandalkan. Tentu saja, keinginan mereka tidak harus bekerja dikantoran, mereka dengan ijazah yang hanya SD dan SMP, tidaklah mungkin untuk mendapatkan penghasilan yang layak dengan meniti karir di perusahaan atau Instansi Pemerintah.

Kelanjutan dari pembicaraan informal telah dapat disimpulkan bahwa mereka menginginkan untuk bisa berusaha sendiri (berwirausaha) yang memiliki core bisnis dengan keterampilan mereka yaitu jasa perbengkelan sepeda motor. Hal ini didasarkan pada pendapat mereka juga bahwa sepeda merupakan kendaraan utama di wilayah mereka dan merupakan harta yang menjadikan gengsi mereka meningkat. Untuk itu memelihara sepeda motor tentu memerlukan jasa perawatan yang tidak mungkin bisa dilakukan sendiri oleh pemilik (Nitisemito, 1996).

Dengan demikian, mitra perlu dikembangkan dalam dua aspek, yaitu pada aspek produksi disepakati untuk meningkatkan keterampilan teknik perawatan dan service sepeda motor untuk tune-up dan dapat mengoperasikan peralatan reparasi secara benar (Rahman \& Elshap, 2016). Aspek kedua yang diperlukan yaitu aspek manajemen usaha (Sakban et al, 2019). Hal ini diperlukan pelatihan untuk meningkatkan skill di bidang pengelolaan usaha, mulai dari manajemen keuangan dasar/sederhana sampai dengan bagaimana mengelola SDM yang nantinya akan menjadi permasalahan yang harus dihadapi oleh kelompok mitra dalam mengatur aktivitas mereka (Saks \& Haccoun, 2010).

Kabupaten Ogan Ilir merupakan hasil pemekaran Kabupaten Ogan Komering Ilir yang dibentuk melalui Undang-undang Nomor 37 Tahun 2003 dan diresmikan pada tanggal 07 Januari 2004. Secara keseluruhan luas wilayah Kabupaten Ogan Ilir adalah $2,666,07 \mathrm{~km}^{2}$ yang terdiri dari $65 \%$ daratan
$35 \%$ rawa.

Wilayah Kabupaten Ogan Ilir terbagi dalam 16 kecamatan dan masing-masing kecamatan terbagi atas 27 desa-desa dan 14 kelurahan (Dinas Pekerjaan Umum Kabupaten Ogan Ilir, 2020). Sedangkan setiap desa-desa dan kelurahan di dalamnya terdiri atas dusun, lingkungan maupun rukun warga (Badan Pusat Statistik Kabupaten Ogan Ilir, 2017).

Gambar 1. Peta Daerah Ogan Ilir (Dinas Pekerjaan Umum Kabupaten Ogan Ilir, 2020)

Pata tahun 2015 tercatat jumlah penduduk sebanyak 409.171 jiwa, sedangkan di tahun 2016 mengalami kenaikan menjadi 414.504 jiwa dengan laju pertumbuhan penduduk 1,30 (Badan Pusat Statistik Kabupaten Ogan Ilir, 2017). Jika diasumsikan satu keluarga berjumlah 4 orang. Maka jumlah keluarga di Ogan Ilir 103,626.

Menurut UPTD Dispenda Kabupaten Ogan Ilir pada tahun 2015 jumlah sepeda motor dan sejenis berjumlah 31598 unit, sedangkan di tahun 2016 berjumlah 38778 unit (Badan Pusat Statistik Kabupaten Ogan Ilir, 2017). Berdasarkan jumlah data keluarga dan jumlah sepeda motor dan sejenisnya, didapatkan $37,42 \%$ masyarakat ogan ilir memiliki kendaraan roda 2 dan sejenisnya (Badan Pusat Statistik Kabupaten Ogan Ilir, 2017).

Di Sekitar UNSRI ada 4 kecamatan yaitu Indralaya, Indralaya Utara, Indralaya Selatan, dan Tanjung Raja. Jika diasumsikan 1 kecamatan ada 25 desa (Ogan Ilir, 2020), dimana 1 desa memiliki 100 keluarga maka kendaraan bermotor yang ada di sekitar UNSRI 3742 unit. Besarnya jumlah kendaraan bermotor ini adalah peluang besar untuk membuka bengkel perbaikan dan perawatan sepeda motor.

Pengabdian masyarakat ini berupa 
pelatihan perawatan dan service sepeda motor yang bertujuan memberikan pelatihan keterampilan perawatan dan service sepeda motor untuk tune-up dan dapat mengoperasikan peralatan reparasi secara benar, memberikan pelatihan untuk skill dalam bidang mengelola usaha.

Sepeda motor adalah kendaraan beroda dua yang digerakkan oleh sebuah mesin yang terdiri atas berbagai komponen dalam operasinya mendapatkan berbagai beban gesekan, tekanan, benturan, pukulan, puntiran, gaya tekan-tarik-tekuk, beban panas, beban kimia dan sebagainya (Sahri, 2019).

Semakin lama digunakan komponen kendaraan pasti akan semakin halus, semakin longgar, semakin lemah, atau semakin menyimpang kepresisiannya dari kondisi semula yang baik dan standar (Yolanda, 2012). Oleh karena itu, maka kendaraan harus mendapatkan perawatan yang dapat dikerjakan oleh bengkel atau dilakukan sendiri secara teratur agar selalu dalam kondisi prima (Hidayat et al, 2018).

Menurut Sahri (2019), tiap bengkel pasti memiliki standard operating procedure (SOP) sebagai panduan mengenai tahapan tune-up, di dalam prosedur yang dilakukan untuk membuat sepeda motor mudah dihidupkan, kerja mesin normal (langsam), serta sistem pengereman yang bekerja dengan baik. Dari segi perawatan sepeda motor dibagi menjadi service ringan dan berat (Arsana et al, 2015).

\section{METODE PENELITIAN}

Tahap awal kegiatan Pengabdian Masyarakat ini dibagi menjadi tiga kegiatan (Yusri, 2017) yaitu pertama, sosialisasi pelaksanaan pengabdian. Kegiatan ini dilakukan untuk memberitahukan dan mensosialisasikan kepada masyarakat setempat terkait program kegiatan masyarakat pelatihan perawatan dan service sepeda motor yang pelaksana pengabdian lakukan dengan kelompok mitra. Output yang dihasilkan berupa terdaftarnya peserta pelatihan sebanyak 15 orang. Dengan ketentuan pemuda putus sekolah ataupun yang belum mendapatkan pekerjaan.

Kedua, kelengkapan alat. Kegiatan ini dilakukan untuk pengadaan alat dan bahan pelatihan kegiatan ini dilakukan untuk menginventarisasi kebutuhan pelatihan perawatan dan service sepeda motor baik yang berupa peralatan maupun bahan yang digunakan.

Ketiga, tes awal. Kegiatan ini dilakukan untuk melihat bagaimana pemahaman materi peserta pelatihan perawatan dan service sepeda motor. Soal yang diberikan dalam bentuk pilihan ganda yang terdiri dari 25 soal.

Tahap selanjutnya yaitu tahap pelaksanaan kegiatan, tahap ini dibagi menjadi tiga tahap yaitu (Malik, 2008) pertama pemberian materi. Pemberian Materi menggunakan metode ceramah dan diskusi, secara umum program pelatihan perawatan dan service sepeda motor ini bertujuan untuk menghasilkan peserta yang memiliki pengetahuan teknik otomotif, keterampilan kerja, serta hak dan tanggung jawab dalam bidang perawatan dan service sepeda motor

Kedua, metode demonstrasi dan praktik. Narasumber dalam pelatihan ini langsung menunjukkan bagaimana perawatan dan service sepeda motor. Narasumber juga langsung mempraktikkan perawatan service sepeda motor. Pelaksanaan praktik perawatan dan service sepeda motor meliputi kegiatan bongkar pasang engine yang sudah dijabarkan pada modul pelatihan. Dari kegiatan praktik ini, peserta diharapkan dapat melakukan perawatan dan service sepeda motor berikut sistem-sistemnya agar kondisi sepeda motor sesuai dengan standar spesifikasinya, mencakup kemampuan, antara lain; Mengidentifikasi, menggunakan, dan memelihara alat tangan (hand tools) dan alat ukur (measurement tools)

Ketiga, pemberian materi wirausaha. Tujuan pemberian materi wirausaha agar para peserta pelatihan ini mempunyai wawasan tentang wirausaha, mampu merencanakan secara sederhana sebuah usaha perbengkelan apabila nantinya ingin membuka usaha mandiri.

Tahap selanjutnya yaitu tahap akhir pelaksanaan, dibagi menjadi 3 (Nainggolan et al., 2017) pertama, tes akhir. Kegiatan ini dilakukan untuk melihat bagaimana pemahaman materi peserta setelah mengikuti pelatihan perawatan dan service sepeda motor. Soal yang diberikan dalam bentuk pilihan 
ganda yang terdiri dari 25 soal. Hasil tes akhir ini akan terlihat bagaimana pemahaman peserta pelatihan perawatan dan service sepeda motor setelah mengikuti pelatihan.

Kedua, evaluasi pelatihan. Evaluasi Pelatihan Pelaksanaan kegiatan pengabdian masyarakat ini bertujuan untuk meningkatkan pengetahuan dan keterampilan masyarakat. Peserta pelatihan merupakan pemuda-pemuda putus, sehingga dengan adanya kegiatan ini diharapkan dapat menjadi pemuda yang berswakarya dan dengan wirausaha di bidang otomotif. Selama pelatihan berlangsung dilakukan tahapan evaluasi untuk mengukur seberapa jauh tingkat pemahaman dan pencapaian kompetensi teknik perawatan dan service sepeda motor yang telah ditetapkan.

\section{HASIL DAN PEMBAHASAN}

\subsection{Hasil}

Kegiatan pengabdian ini sudah dilaksanakan dalam waktu kurang dua (2) bulan dimulai dari tahap persiapan antara lain, penyusunan rencana pengabdian, observasi, penyusunan proposal dan dilanjutkan tahap pelaksanaan yang diawali dengan pembuatan modul pelatihan, merumuskan dan membuat instrumen tes dan observasi, kelengkapan fasilitas, dan pelaksanaan pelatihan hingga tahap penyusunan laporan (Carpenter-Aeby \& Aeby, 2013).

Peserta yang menjadi khalayak sasaran kegiatan ini berjumlah 15 peserta yaitu masyarakat atau pemuda putus sekolah yang berada di Kelurahan Permata Baru (Mandala) Kecamatan Indralaya Utara Ogan Ilir. Pelaksanaan kegiatan ini sepakati dilaksanakan di Laboratorium Pendidikan Teknik Mesin Universitas Sriwijaya. Kegiatan pelatihan dan service sepeda motor dilakukan selama 3 hari pada tanggal 16 s/d 18 November 2020.

Pada tahap awal, seluruh peserta dikumpulkan dan diberikan evaluasi awal untuk melihat bagaimana tingkat pemahaman peserta pelatihan perawatan dan service sepeda motor yang nantinya akan dibandingkan dengan tes akhir (pre-test).

Selanjutnya tahap pelaksanaan kegiatan. Setelah melewati pengambilan data awal yaitu pre-test. Peserta pelatihan akan diberikan pemahaman secara awal secara umum tentang materi pelatihan yang berhubungan dengan perawatan dan service sepeda motor lebih lengkap, sehingga peserta akan paham tentang materi yang disampaikan.

Materi yang diberikan menggunakan metode ceramah yang salah satunya mempergunakan media proyektor sebagai hasil proyeksi dari materi yang dijelaskan dan juga menggunakan alat peraga. Alat peraga digunakan secara langsung untuk mengaplikasikan dari materi teori yang diberikan. Metode ini disampaikan langsung kepada peserta pelatihan, untuk lebih jelasnya bisa lihat pada Gambar 2.

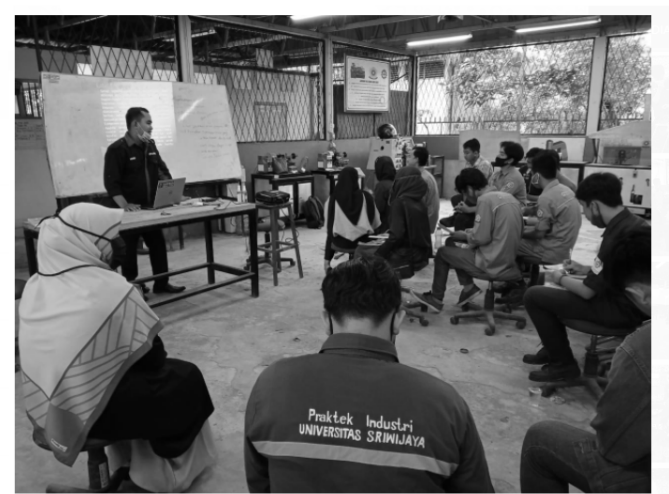

Gambar 2. Pemberian materi secara ceramah dan diskusi

Adapun Materi dan Narasumber yang terangkum pada modul, dapat dilihat pada Tabel 1 di bawah ini: 
Tabel 1 Materi dan Narasumber Pelatihan Perawatan dan service sepeda motor

\begin{tabular}{|c|c|c|}
\hline No & Materi Pelatihan & Nara Sumber \\
\hline 1 & $\begin{array}{l}\text { Tune up sepeda motor. } \\
\text { 1. pemeriksaan saringan udara } \\
\text { 2. pemeriksaan busi } \\
\text { 3. stel karburator } \\
\text { 4. pemeriksaan lampu dan sistem kelistrikan } \\
\text { 5. pemeriksaan dan stel rem } \\
\text { 6. stel klep } \\
\text { 7. pemeriksaan rantai }\end{array}$ & $\begin{array}{l}\text { Wadirin, S.Pd., M.Pd } \\
\text { Moderator: Dewi Puspita Sari, } \\
\text { S.Pd., M.Pd }\end{array}$ \\
\hline 2 & $\begin{array}{l}\text { Servis sistem bahan bakar } \\
\text { 1. pemeriksaan tangki bahan bakar } \\
\text { 2. pemeriksaan saringan bahan bakar } \\
\text { 3. pemeriksaan karburator, membersihkan karburator, } \\
\text { pemeriksaan slow jet dan main jet, pemeriksaan jarum dan } \\
\text { pelampung. } \\
\text { 4. setel campuran bahan bakar dan } \\
\text { 5. } \text { setel rpm mesin sepeda motor }\end{array}$ & $\begin{array}{l}\text { Wadirin, S.Pd., M.Pd } \\
\text { Moderator : Dewi Puspita Sari, } \\
\text { S.Pd., M.Pd }\end{array}$ \\
\hline 3 & $\begin{array}{l}\text { Kewirausahaan teknologi sepeda motor } \\
\text { 1. peluang pasar untuk servis sepeda motor } \\
\text { 2. masih langka bengkel yg sesuai standar } \\
\text { 3. pengguna sepeda motor terus meningkat setiap tahunnya. } \\
\text { 4. masih kurang tenaga profesional untuk servise sepeda } \\
\text { motor. } \\
\text { 5. kebutuhan servis yg terjangkau bagi masyarakat. }\end{array}$ & $\begin{array}{l}\text { Wadirin, S.Pd., M.Pd } \\
\text { Moderator : Dr. Dendy Adanta, } \\
\text { S.Pd. M.T }\end{array}$ \\
\hline
\end{tabular}

\subsection{Pembahasan}

Untuk langkah pembahasan, peserta pelatihan menggunakan modul dan jobsheet sebagai bahan materi yang akan digunakan dalam diskusi dan pembelajaran. Modul yang diberikan di desain sedemikian sederhana, tetapi isi materi di dalam modul lengkap dengan petunjuk kerja dan gambar kerja, dengan tujuan memudahkan peserta pelatihan memahami materi yang disampaikan.

Selain metode ceramah dan diskusi, dalam pengabdian ini juga menggunakan metode demonstrasi. Metode ini dilakukan langsung oleh narasumber kepada peserta pengabdian masyarakat ini. Metode ini dipilih dengan tujuan peserta lebih mengerti bagaimana perawatan dan service sepeda motor. Untuk metode demonstrasi dapat dilihat pada Gambar 3 dibawah ini. Gambar 3 adalah kegiatan perbaikan sistem pembakaran.

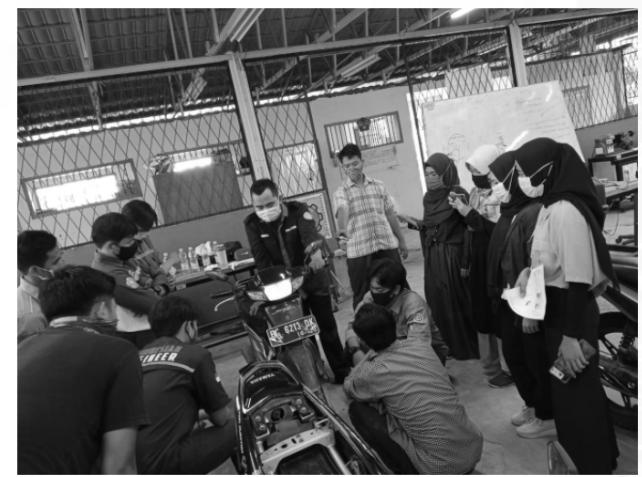

Gambar 3. Pemberian materi secara Demonstrasi

Selanjutnya peserta pelatihan akan terjun langsung untuk melaksanakan praktik perawatan dan service sepeda motor. Kegiatan ini didampingi dan dibimbing oleh narasumber pelatihan perawatan dan service sepeda motor langsung. Untuk lebih jelas dapat dilihat pada Gambar 4. Gambar 4 adalah perbaikan dan pembersihan sistem karburator. 


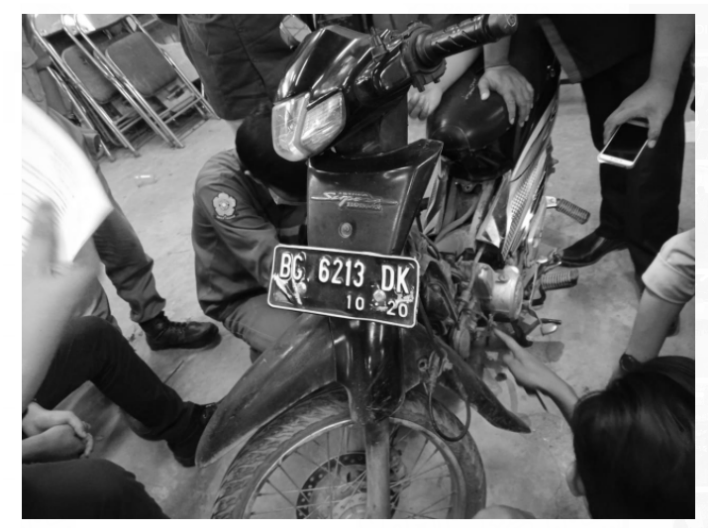

Gambar 4. Praktik Perawatan dan Service Sepeda Motor

Tahap akhir kegiatan ini yaitu evaluasi akhir. Tujuan akhir dari kegiatan pengabdian ini adalah memberikan pengetahuan dan pemahaman terhadap bagaimana cara melakukan perawatan dan service sepeda motor. Penilaian keberhasilan dari kegiatan ini dapat dilihat melalui kemajuan pengetahuan dan pemahaman serta keterampilan melalui perbandingan antara tes awal dan tes akhir (Rusdiana, 2020). Hal ini dapat dilihat pada rekapitulasi nilai pelatihan pada Tabel 2. Dari Table 2 terlihat ada peningkatan pemahaman sebelum dan setelah dilakukan pelatihan.

Tabel 2. Rekapitulasi Nilai Pelatihan Perawatan dan Service Sepeda Motor

\begin{tabular}{cccc}
\hline No & Nama & $\begin{array}{c}\text { Nilai tes awal } \\
\text { (pre-test) }\end{array}$ & $\begin{array}{c}\text { Nilai tes akhir } \\
\text { (post-test) }\end{array}$ \\
\hline 1 & TL & 40 & 88 \\
\hline 2 & ES & 36 & 72 \\
\hline 3 & HS & 48 & 80 \\
\hline 4 & RA & 48 & 84 \\
\hline 5 & SIA & 40 & 80 \\
\hline 6 & FSR & 36 & 76 \\
\hline 7 & WF & 52 & 88 \\
\hline 8 & HM & 64 & 92 \\
\hline 9 & MA & 40 & 88 \\
\hline 10 & WE & 44 & 80 \\
\hline 11 & MH & 52 & 92 \\
\hline 12 & AA & 36 & 88 \\
\hline 13 & EO & 40 & 80 \\
\hline 14 & RDY & 52 & 88 \\
\hline 15 & IR & 52 & 80 \\
\hline
\end{tabular}

Grafik peningkatan keahlian peserta sebelum dan sesudah pelatihan

\section{0 \\ $\begin{array}{cc}50 & 1\end{array}$ \\ TL HS SIA WF MA MH EO IR}

Nilai tes awal (Pre test) $\square$ Nilai tes akhir (post test)

Gambar 5. Grafik peningkatan keahlian peserta sebelum dan sesudah pelatihan

Kegiatan pelatihan ini juga dapat memotivasi dan meningkatkan keahlian masyarakat khususnya pemuda putus sekolah untuk membuka usaha sendiri yaitu service sepeda motor. Hasil dari kegiatan pelatihan dan pengabdian masyarakat ini yaitu:

1. Tersedianya peralatan perawatan dan service sepeda motor

Berdasarkan analisis situasi bahwa salah satu masalah yang dihadapi para peserta pelatihan pengabdian masyarakat ini adalah tidak memiliki peralatan untuk perawatan dan service sepeda motor. Adapun pengadaan alat ini diserahkan kepada peserta pelatihan pengabdian masyarakat, untuk digunakan sebaik mungkin (Gambar 6).

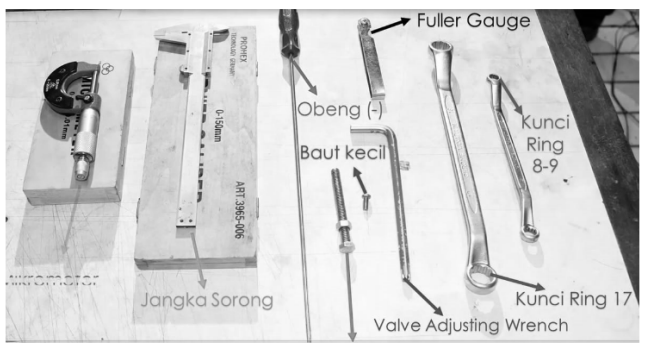

Gambar 6. Peralatan Perawatan dan service sepeda motor

2. Menghasilkan SDM berkualitas dalam arti peserta pelatihan ini bisa melakukan perawatan dan service sepeda motor dan mampu menciptakan lapangan pekerjaan yang dapat meningkatkan taraf hidup.

3. Ketersedian buku panduan (modul) dan jobsheet

Buku panduan ini digunakan sebagai referensi dalam pelaksanaan praktik perawatan dan service sepeda motor, modul dan jobsheet ini juga digunakan untuk mempermudah dalam praktik di lapangan. Modul dan jobsheet dapat dilihat pada Gambar 7 dan 8. 


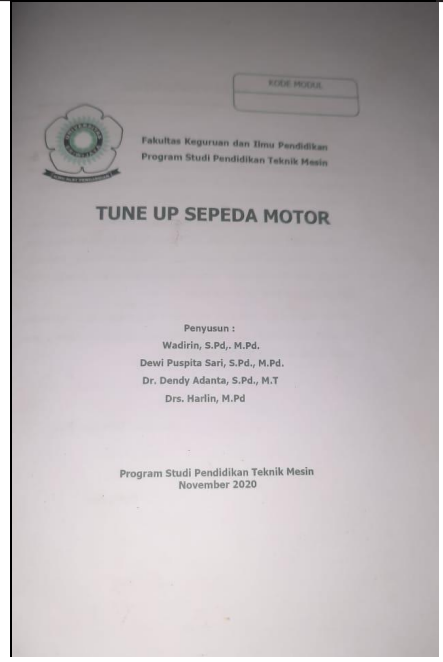

Gambar 7. Modul pelatihan Perawatan dan service sepeda motor

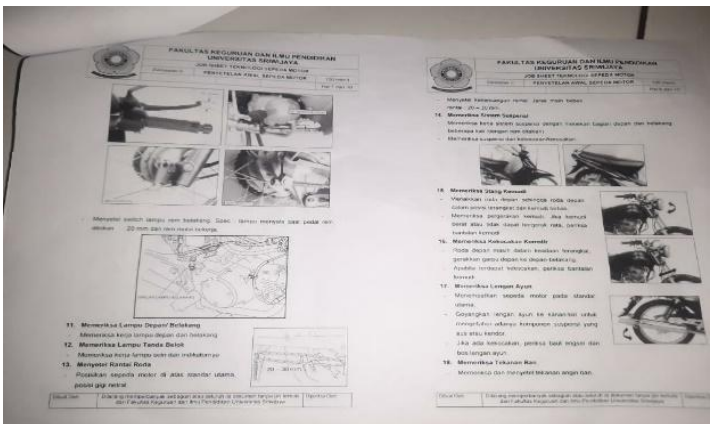

Gambar 8. Job-sheet pelatihan perawatan dan service sepeda motor

4. Pendampingan usaha dengan memberikan materi tentang berwirausaha dengan tujuan peserta pelatihan dapat membuka peluang usaha perawatan dan service sepeda motor.

\section{KESIMPULAN}

Berdasarkan dari hasil pelaksanaan kegiatan pelatihan perawatan dan service sepeda motor, dapat disimpulkan sebagai berikut: Pengetahuan masyarakat khususnya pemuda putus sekolah di kelurahan permata baru (mandala) masih kurang sebelum dilaksanakan pengabdian masyarakat ini. Hal ini bisa dilihat dari hasil tes awal sebelum dilaksanakan kegiatan pelatihan.

Penyampaian materi dengan menggunakan metode ceramah, diskusi, demonstrasi, dan praktik berjalan efektif, dilihat dari antusias peserta pelatihan mengikuti kegiatan pengabdian masyarakat ini, dan hasil akhir dari tes terjadi peningkatan signifikan terhadap pemahaman peserta tentang perawatan dan service sepeda motor.

Dengan tersedianya modul dan jobsheet serta tools yang memadai peserta mempunyai peluang untuk membuka lapangan kerja yang berhubungan dengan perawatan dan service sepeda motor sehingga meningkatkan taraf hidup.

Berdasarkan hasil rekapitulasi nilai akhir, dan perbandingan nilai akhir dan awal terjadi peningkatan signifikan. Dapat disimpulkan bahwa peserta pelatihan mengalami peningkatan pengetahuan, pemahaman serta skill setelah diadakan pengabdian ini. 


\section{DAFTAR PUSTAKA}

Arsana, I. M. J., Aryanta, I. W. R., \& Sudana, I. B. (2015). Kajian Kualitas Lingkungan Kerja dan Penerapan Standar Operasional Prosedur Bengkel Servis Kendaraan Terhadap Kesehatan Pekerja Mekanik Sepeda Motor di Kota Denpasar. Ecotrophic Jurnal, 9 (2), 64-72.

Badan Pusat Statistik Kabupaten Ogan Ilir. (2017). Kabupaten Ogan Ilir dalam Angka. Indralaya.

Carpenter-Aeby, T., \& Aeby, V. G. (2013). Application of andragogy to instruction in an MSW practice class. Journal of Instructional Psychology, 40.

Dinas Pekerjaan Umum Kabupaten Ogan Ilir. (2020). Satuan Tugas Penyusun RPI2-JM: BAB IV Profil Kabupaten Ogan Ilir. In Satuan Tugas Penyusunan RPI2-JM. Indralaya. Retrieved from sippa.ciptakarya.pu.go.id

Hidayat, N., Arif, A., Setiawan, M. Y., \& Afnison, W. (2018). Peningkatan Pengetahuan dan Keterampilan Pemuda Putus Sekolah Melalui Pelatihan Perawatan Berkala Sepeda Motor. INVOTEK: Jurnal Inovasi Vokasional Dan Teknologi, 18(2), 83-90.

Malik, H. (2008). Teori Belajar Andragogi Dan Aplikasinya dalam Pembelajaran. Jurnal Inovasi, 5(2).

Nainggolan, E., Mariah, S., \& Kurniawan, F. (2017). Internalisasi Asumsi Pembelajaran Andragogi Pada Mata Kuliah Statistik. Jurnal Keluarga Sehat Sejahtera, 15(1).

Nitisemito, A. S. (1996). Manajemen personalia. Jakarta: Ghalia Indonesia.

Ogan Ilir. (2020). Sensus Penduduk Online 2020, Sukseskan Satu Data Kependudukan. Retrieved from http://www.oganilirkab.go.id

Rahman, A., \& Elshap, D. S. (2016). Implementasi kekuatan motivasi belajar dalam pendekatan andragogi. EMPOWERMENT: Jurnal Ilmiah Program Studi Pendidikan Luar Sekolah, 5(2), 1-12.

Rusdiana, A. (2020). Andragogi: Metode dan Teknik Memanusiakan Manusia. Pusat Penelitian dan Penerbitan UIN Sunan Gunung Djati Bandung.

Sahri, A. (2019). Manajemen Kurikulum Program Studi Pengujian Kendaraan Bermotor (PKB) untuk Meningkatkan Mutu Lulusan di Politeknik Keselamatan Transportasi Jalan (PKTJ). DISERTASI dan TESIS Program Pascasarjana UM.

Sakban, S., Nurmal, I., \& Bin, R. R. (2019). Manajemen sumber daya manusia. Alignment: Journal of Administration and Educational Management, 2(1), 93-104.

Saks, A. M., \& Haccoun, R. R. (2010). Managing performance through training and development. Toronto, Canada.

Yolanda, Y. (2012). Hubungan Kapasitas Mesin Dan Tahun Pembuatan Serta Perawatan Kendaraan Bermotor Dengan Emisi Gas Buang Kendaraan Bermotor Di Kota Medan Tahun 2012. PS Kesehatan Masyarakat USU. Medan.

Yusri, Y. (2017). Strategi Pembelajaran Andragogi. Al-Fikra: Jurnal Ilmiah Keislaman, 12(1), $25-52$. 